\title{
Ad Length and the Presence of the Timer in In-Stream Commercial: An Abstract
}

\author{
Yongwoog Jeon, Hyunsang Son, and Arnold D. Chung
}

\begin{abstract}
One of the most prominent phenomena in the online environment is the rapid growth of the in-stream commercial, where video advertising appears before, during, and/or after viewers watch their chosen content (YouTube, 2016). However, a limited number of scholarly articles have investigated the factors affecting individuals' avoidance of the advertising exposure - mainly based on the traditional commercial context (e.g., zapping behavior for television commercials) - by focusing on the cognitive aspect of the decision-making process. Thus, we proposed two important features that might influence the consumers' irritation level: the length of in-stream commercials and the existence (versus absence) of the countdown timer based on the concept of temporal uncertainty (Monat, 1976; Zakay, 1992) from the uncertainty theory (Knight, 1921).

The study employed a 2 (length of ad, $15 \mathrm{~s}$ vs. $30 \mathrm{~s}$ ) $\times 2$ (timer: presence vs. absence $) \times 2$ (disruption situation: in-stream commercial before the movie trailer vs. viewing the in-stream commercial only) between-subject randomized experiment, with 264 MTurk users.

We found the main effects of advertising length for consumers' perceptions of the advertising value $\left(M_{15 \mathrm{~s}}=3.49, \mathrm{SD}=1.48\right.$ vs. $M_{30 \mathrm{~s}}=4.04, \mathrm{SD}=1.71 ; F(1$, $216)=6.40$, partial $\left.\eta^{2}=0.029, p<0.05\right)$ and perceived informativeness $\left(M_{15 \mathrm{~s}}=3.82\right.$, $\mathrm{SD}=1.50$ vs. $M_{30 \mathrm{~s}}=4.36, \mathrm{SD}=1.56 ; F(1,216)=7.00$, partial $\left.\eta^{2}=0.031, p<0.01\right)$, but we failed to find the main effects of the time cue. Thus, contrary to our assumption of the negative relationship between the length of the ad and consumer's evaluation of the advertisement, the longer advertisement (i.e., 30-s ad) was considered more valuable and informative for the consumer. Although statistically not significant, this pattern was similar for our main interest: consumer irritation. Those who viewed the shorter version of the ad felt more irritation $\left(M_{\text {irritation }}=3.19, \mathrm{SD}=1.49\right)$ and exhibited a higher level of irritation compared to those who viewed the longer version of the in-stream advertising $\left(M_{\text {irritation }}=2.93,1.62\right)$.
\end{abstract}

References Available Upon Request

Y. Jeon $\bullet$ H. Son $(\bowtie) \bullet$ A.D. Chung

The University of Texas, Austin, TX, USA

e-mail: yongwoog@utexas.edu; hyunsangson@utexas.edu; adwc86@utexas.edu

(C) Academy of Marketing Science 2018

N. Krey, P. Rossi (eds.), Back to the Future: Using Marketing Basics to Provide

Customer Value, Developments in Marketing Science: Proceedings of the

Academy of Marketing Science, DOI 10.1007/978-3-319-66023-3_3 